\title{
Habitat preference and activity of the noctule bat Nyctalus noctula in the Bialowieża Primeval Forest
}

\author{
Alek RACHWALD
}

\begin{abstract}
Rachwald A. 1992. Habitat preference and activity of the noctule bat Nyctalus noctula in the Białowieża Primeval Forest. Acta theriol. 37: 413 - 422 .

The echolocation calls of the noctule bat Nyctalus noctula (Schreber, 1774) were recorded at night, from June to August 1991, using a QMC S200 bat detector, in 5 habitats (river, forest-meadow ecotone, village, coniferous forest, deciduous forest) of the Białowieża Primeval Forest (eastern Poland). Two main kinds of signals were identified: search calls and feeding buzzes. Acoustic activity was high over the rivers, in the forest-meadow ecotone and in small woodland villages. It was negligible inside the coniferous and deciduous forests. The differences among habitats were especially evident in the case of feeding buzzes; no feeding was recorded inside deep deciduous forests. Two peaks in overnight activity were found, with maxima after sunset and before sunrise. Intraseasonal changes of activity were recorded; the highest activity was in July.

Mammal Research Institute, Polish Academy of Sciences, 17-230 Białowieża, Poland

Key words: Nyctalus noctula, habitat preference, activity, echolocation, Białowieża Primeval Forest, Poland
\end{abstract}

\section{Introduction}

The occurrence of the noctule bat Nyctalus noctula (Schreber, 1774) is bound closely to wooded areas. Both the summer activity of the bat and its hibernation are connected with hiding-places in forests, although the animal occurs in towns, too (Gaisler et al. 1979, Kowalski and Ruprecht 1983). In spite of the fact that the species is wide-spread and relatively common, many aspects of its life remain unexamined. The summer and winter hiding-places of the bat are comparatively difficult to reach, and the distances between day roosts and foraging areas are usually long. That is why little is known about the ecology and behavior of the noctule bat. Its foraging activity and 24-hour rhythm have not been studied yet, except in the work by Kronwitter (1988).

The aim of this work is to examine, with the use of recordings and the interpretation of ultrasonic signals, habitat preferences of the noctule bat in the varying landscape of the Białowieża Primeval Forest, as well as to study the overnight and seasonal rhythms of the bat's flight activity. 


\section{Study area}

The Białowieża Primeval Forest $\left(1,250 \mathrm{~km}^{2}\right)$ is the only preserved European fragment of the lowland primeval forests of the boreal zone. Except for areas partly degraded by forest-management, it comprises areas covered with slightly changed plant communities (forests and others), rivers, riversides, and areas utilized for traditional farming. The oldest and best preserved part of the primeval forest, lying between the Narewka and the Hwozna rivers, constitutes the Białowieża National Park (BNP) $\left(52^{\circ} 43^{\top} \mathrm{N}, 23^{\circ} 54^{\prime} \mathrm{E}, 47.5 \mathrm{~km}^{2}\right)$. The average age of trees in the BNP is 130 years (300-400 being the maximum). The most frequent forest communities are: deciduous oak-lindenhornbeam forest (Tilio-Carpinetum), streamside alder-ash forest (Circaeo-Alnetum), mixed forest (Pino-Quercetum), and spruce forest (Querco-Piceetum) (Faliński 1986). For this work, ten study sites were placed in pairs in five selected habitats on the territory of the BNP and its vicinity (Fig. 1). The habitats were:

(1) River: the banks of the Narewka (1a) and the Hwonna (1b) on the borderline of the BNP. The area was flat, covered with reed and meadow plants (Phragmites communis and Carex spp.), and partly undergoing the secondary forest succession. The distances from the edge of a black alder bog forest (Carici elongatae-Alnetum) were $50 \mathrm{~m}$ in $1 \mathrm{a}$ and $30 \mathrm{~m}$ in $1 \mathrm{~b}$.

(2) Forest edge (forest-meadow ecotone): between a deciduous forest (Tilio-Carpinetum) and a meadows undergoing secondary forest succession belonging to the protective zone of the BNP, called the Białowieża Glade. The sites $2 \mathrm{a}$ and $2 \mathrm{~b}$ were $2.5 \mathrm{~km}$ away from each other. Their distance from farm buildings was at least $500 \mathrm{~m}$ of open space.

(3) Woodland village: Pogorzelce (3a; 70 inhabitants) and Teremiski (3b; 100 inhabitants), located on clearings about $1.5 \mathrm{~km}$ in diameter and used also as fields and grass-lands. Most of the farm

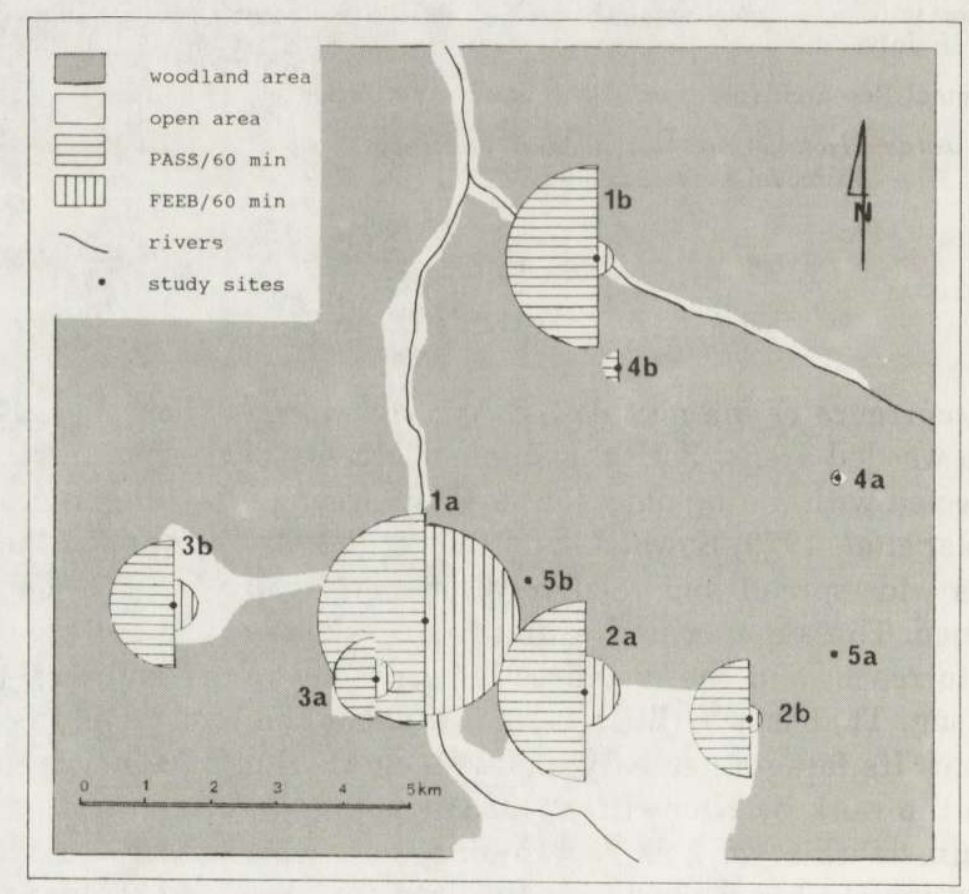

Fig. 1. Schematic map of the study area. Comparison of the noctule bat activity in particular study sites. $1 \mathrm{a}, \mathrm{b}$ - river; $2 \mathrm{a}, \mathrm{b}$ - forest edge; $3 \mathrm{a}$, b - village; $4 \mathrm{a}$, b - coniferous forest; $5 \mathrm{a}, \mathrm{b}$ - deciduous forest. 
buildings and dwelling houses were wooden. The recordings were made on asphalt roads (4 $\mathrm{m}$ wide) crossing the villages. There were no lamps along the roads.

(4) Coniferous forest: a spruce forest (Querco-Piceetum) and, partly, a mixed forest (PinoQuercetum) on the territory of the BNP. The recordings were made on a cart-road about $3 \mathrm{~m}$ wide. The predominant tree species near both the sites was the spruce Picea abies consisting 40 percent of the forest. The other species were: pine Pinus silvestris, oak Quercus robur, aspen Populus tremula, and birch Betula verrucosa. The age of the trees varied from 70 to 130 years.

(5) Deciduous forest: a deciduous oak-linden-hornbeam forest (Tilio-Carpinetum) on the territory of the BNP. The recordings were made on a cart-road about $3 \mathrm{~m}$ wide. The predominant tree species near both the sites were the following: (for $5 \mathrm{a}$ ) linden Tilia cordata $(30 \%)$ and hornbeam Carpinus betulus $(30 \%)$, with admixtures of oak, maple Acer platanoides and spruce; (for $5 \mathrm{~b}$ ) oak (40\%) and hornbeam $(30 \%)$, with admixtures of linden and maple. The age of the trees varied from 70 to 200 years.

\section{Methods}

Each study site was visited 3 times (a total of 30 visits, 134 hours) from 1 June to the end of August 1991. Only one site was visited during one night. The sequence of visited sites was always the same: $2 \mathrm{a}, 2 \mathrm{~b}, 1 \mathrm{a}, 5 \mathrm{a}, 4 \mathrm{a}, 5 \mathrm{~b}, 4 \mathrm{~b}, 1 \mathrm{~b}, 3 \mathrm{a}, 3 \mathrm{~b}$. The recordings were made during four 60 -min sessions in one study site per one night. The first recording hour began $30 \mathrm{~min}$ after sunset, and the fourth one ended $30 \mathrm{~min}$ before sunrise. The time of the remaining two 60 -min sessions (one before midnight and one after midnight) were chosen in such a way so that all the four periods were separated with equal intervals. So, the time of the observations changed throughout the season because of different hours of sunrise and sunset from June to August.

In each site four spots were selected. The spots formed a row, and the distance between subsequent spots was $100 \mathrm{~m}$. In each of them recordings lasted $15 \mathrm{~min}$, which amounted to one 60 -min session of registration in each site. The reason for changing the spots was to control for variation within sites (Thomas 1988).

The data about air temperature were taken from a weather-station, located in the Białowieża Glade. The minimum night temperatures $\left(t_{\min }\right)$ in June varied from $3.7^{\circ} \mathrm{C}$ to $16.1^{\circ} \mathrm{C}\left(\bar{x}=10.2^{\circ} \mathrm{C}\right)$, in July - from $10.2^{\circ} \mathrm{C}$ to $15.1^{\circ} \mathrm{C}\left(\bar{x}=11.5^{\circ} \mathrm{C}\right)$, and in August - from $7.2^{\circ} \mathrm{C}$ to $19.1^{\circ} \mathrm{C}\left(\bar{x}=12.8^{\circ} \mathrm{C}\right) .11^{\circ} \mathrm{C}$ was taken as the border figure for searching the dependence of the overnight activity rhythm of bats on air temperature. It was taken into consideration that in the European weather conditions, temperatures between 5 and $10^{\circ} \mathrm{C}$ are considered to be the thermic minimum for hunting bats (e.g. Erkert 1982). The recordings were carried on during rainless nights.

Activity was assessed by counting the number of bat passes and feeding (terminal) buzzes during a 60-minute observation at each site. A sequence of 2 echolocational pulses of a passing bat was considered as one pass (Furlonger et al. 1987, Thomas 1988). Most frequently, the signals were search calls, which are combinations of signals FM (frequency modulated) and those similar to CF (constant frequency). One continual final sequence of FM signals, the one which accompanies catching prey (Griffin et al. 1960), was taken for a single feeding buzz (FEEB).

The equipment used was a QMC S200 bat detector, which converts ultrasounds to audible frequencies, operated in TUNED (heterodyne) mode. The frequency value was fixed on $22 \mathrm{kHz}$, which gave the range of about 17 to $27 \mathrm{kHz}$, and enabled the recording of noctule bats' signals with maximum intensity (Ahlén 1981, Miller and Degn 1981). It also allowed to effective separation of the signals of noctule bats from calls of concomitant species (e.g. the serotine bat Eptesicus serotinus), for which the elements of maximum intensity are of higher frequency. A monophonic SANYO M1115 tape-recorder and cassettes type I were used to record the echolocations. In order to verify the registrations, recordings of European bats' voices were compared (Ahlén 1989), and when possible, visuall observations were applied. 
Because the frequency distribution of data greatly departed from normality (records equalled to zero were most numerous) and no method of transformation managed to make the data meet the assumptions of analysis of variance, I could not use ANOVA for statistical analysis (comp. Sokal and Rohlf 1981). Instead, the distribution-free, nonparametric tests (Kruskal-Wallis $H$ - and MannWhitney $U$-tests) were applied (Sokal and Rohlf 1981).

\section{Results}

\section{Habitat preference}

The noctule bat was recorded in all the studied habitats. The number of passes/60 min of recording was the highest in the 1a site (on the Narewka River), and the lowest in $5 \mathrm{~b}$ (the deciduous forest). Statistically significant differences were found in the number of passes/60 min between all the examined areas (Fig. 1, Table 1). The comparison of the numbers of passes/60 min between all the sites, made with the use of Kruskal-Wallis $H$-test showed that the sample is heterogenic $(H=26.133$, d.f. $=4, p<0.001)$. No significant differences within the pairs of sites belonging to the same habitats were found (Mann-Whitney $U$-test, $U_{\mathrm{s}}$ always $<93.0$, d.f. $=12,12, p>0.1$ ). Therefore, for further analyses, data from the same habitats were combined. The comparison of the numbers of passes $/ 60 \mathrm{~min}$ (Table 1) showed considerable differences between the rivers (habitat 1 ) and the forest edge (forest-meadow ecotone; habitat 2) (Mann-Whitney $U$-test, $U_{\mathrm{s}}=72.0$, d.f. $=$ $8,12, p<0.05$ ), as well as between the woodland villages (habitat 3 ) and the coniferous forest (habitat 4$)\left(U_{\mathrm{s}}=101.5\right.$, d.f. $\left.=12,12, p>0.1\right)$, and also between the coniferous forest (habitat 4) and the deciduous forest (habitat 5) $\left(U_{\mathrm{s}}=81.0\right.$, d.f. $=10,12, p>0.1$.

The highest figures of FEEB/60 min were recorded in the 1a site (the Narewka). In the deciduous forest (habitat 5), the bats did not feed at all (Fig. 1, Table 1). The comparison of the numbers of FEEB/60 min between all the sites, with the

Table 1. The mean numbers and SD of passes/60 min and FEEB/60 $\mathrm{min}$ in particular study sites.

\begin{tabular}{lcrcr}
\hline Study site & PASS/60 min & SD & FEEB/60 min & SD \\
\hline 1a. river & 21.3 & 11.72 & 19.0 & 24.94 \\
1b. river & 18.4 & 7.95 & 3.6 & 4.47 \\
2a. forest edge & 18.0 & 21.44 & 7.0 & 9.76 \\
2b. forest edge & 11.6 & 11.80 & 2.3 & 3.30 \\
3a. village & 8.3 & 8.73 & 3.8 & 6.43 \\
3b. village & 12.6 & 10.97 & 4.9 & 8.50 \\
4a. coniferous forest & 1.5 & 3.85 & 1.2 & 3.60 \\
4b. coniferous forest & 2.3 & 1.88 & 0.2 & 0.55 \\
5a. deciduous forest & 0.7 & 0.75 & 0.0 & 0.00 \\
5b. deciduous forest & 0.9 & 1.66 & 0.0 & 0.00 \\
\hline
\end{tabular}


use of Kruskal-Wallis $H$-test, showed heterogenity of the sample ( $H=14.860$, d.f. $=4, p<0.005$ ). Pairs of sites from the same habitats did not differ significantly from each other (Mann-Whitney $U$-test, $U_{\mathrm{s}}$ always $<93.5$, d.f. $=12,12, p>0.025$ ); therefore, for further analyses, results obtained in the pairs were combined. Noctule bats most often fed at riversides (habitat 1 ) (Mann-Whitney $U$-test, $U_{\mathrm{s}}=$ 72.5 , d.f. $=8,12, p<0.05$ ). The levels of feeding activity for the forest edge (habitat 2 ) and the villages (habitat 3$)$ were similar $\left(U_{\mathrm{s}}=76.5\right.$, d.f. $\left.=12,12, p>0.1\right)$, and the lowest level of activity was in the coniferous forest (habitat 4$)\left(U_{\mathrm{s}}=98.5\right.$, d.f. $=10,12, p<0.01$ ).

\section{Overnight activity}

Mean levels of activity in subsequent hours were compared for habitats in which the activity of noctule bats was higher (river, forest-meadow ecotone, village; Fig. 1). The subsequent hours of night recordings were referred to as $1,2,3$, and 4. The comparison of results with the use of Kruskal-Wallis $H$-test revealed that samples from subsequent night hours were highly homogenic $(H=4.788$, d.f. $=3$, $p>0.1$ ). Only the numbers of passes $/ 60 \mathrm{~min}$ after sunset and before sunrise (hours 1 and 4) were visibly higher than after midnight (hour 3) (Mann-Whitney $U$-test, $1-3: U_{\mathrm{s}}=51.0$ d.f. $=8,8, p<0.05 ; 3-4: U_{\mathrm{s}}=49.5$, d.f. $\left.=8,8, p<0.05\right)$. Similar differences were found for the numbers of $\mathrm{FEEB} / 60 \min (H=6.098$, d.f. $=3, p$ $>0.1$; significant differences between hours after sunset and before midnight (hour 2): $U_{\mathrm{s}}=55.0$, d.f. $=8,8, p<0.025$, as well as after sunset and after midnight: $U_{\mathrm{s}}$ $=55.5$, d.f. $=8,8, p<0.01$ ) (Fig. 2).

Comparing the numbers of $\mathrm{FEEB} / 60 \mathrm{~min}$ in the subsequent hours between nights of $t_{\min }<11^{\circ} \mathrm{C}$ and those with $t_{\min } \geq 11^{\circ} \mathrm{C}$ (Table 2), a dependence of the foraging activity on air temperature was found. In higher temperatures there was an increase in foraging activity in the morning. Such an increase was not noted during cool nights.

Table 2. The significance of differences in the number of FEEB/60 min between particular parts of the night ( 1 - after sunset, 2 - before midnight, 3 - after midnight, 4 - before sunrise) for a night of $t_{\min }$ (the minimum recorded temperature) lower than $11^{\circ} \mathrm{C}$ and higher than or equal to $11^{\circ} \mathrm{C}$.

\begin{tabular}{lcclcll}
\hline Hours & \multicolumn{3}{c}{$t_{\min }<11^{\circ} \mathrm{C}$} & \multicolumn{3}{c}{$t_{\min } \geq 11^{\circ} \mathrm{C}$} \\
& $U_{\mathrm{B}}$ & d.f. & $p$ & $U_{\mathrm{s}}$ & d.f. & $p$ \\
\hline $1-2$ & 75.5 & 10,10 & 0.05 & 29.0 & 7,7 & $\mathrm{~ns}$ \\
$1-3$ & 97.0 & 10,10 & 0.001 & 29.0 & 7,7 & $\mathrm{~ns}$ \\
$1-4$ & 79.0 & 10,10 & 0.025 & 31.5 & 7,7 & $\mathrm{~ns}$ \\
$4-2$ & 54.2 & 10,10 & $\mathrm{~ns}$ & 39.0 & 7,7 & 0.05 \\
$4-3$ & 67.5 & 10,10 & $\mathrm{~ns}$ & 33.0 & 7,7 & $\mathrm{~ns}$ \\
\hline
\end{tabular}




\section{Monthly activity}

In the three habitats where the level of the noctule bat's activity was higher (river, forest-meadow ecotone, village; Fig. 1), an intraseasonal differentiation of the activity was observed. The activity in the three summer months differed significantly (for passes $/ 60 \mathrm{~min}: H=6.936$, d.f. $=2, p<0.05$; for FEEB $/ 60 \mathrm{~min}$ : $H=25.846$, d.f. $=2, p<0.001$, Kruskal-Wallis $H$-test). The numbers of passes $/ 60$ $\mathrm{min}$ and the numbers of FEEB/60 min were the highest in July. The number of passes/60 min from July differed considerably from the corresponding figures from the remaining months (Mann-Whitney $U$-test; June - July: $U_{\mathrm{s}}=104.0$, d.f. $=12,12$, $p<0.05$; July-August: $U_{\mathrm{s}}=118.0$, d.f. $=12,12, p<0.005$ ) while no significant differences were noted between the numbers obtained in June and August $\left(U_{\mathrm{s}}=72.5\right.$ d.f. $\left.=12,12, p>0.1\right)$. For the numbers of FEEB/60 min a similar score was obtained (June - July: $\mathrm{U}_{\mathrm{s}}=128.5$, d.f. $=12,12, p<0.001$; July - August: $U_{\mathrm{s}}=125.0$, d.f. $=12,12, p<0.001$; June - August: $U_{\mathrm{s}}=84.0$, d.f. $=12,12, p>0.1$ ) (Fig. 3).
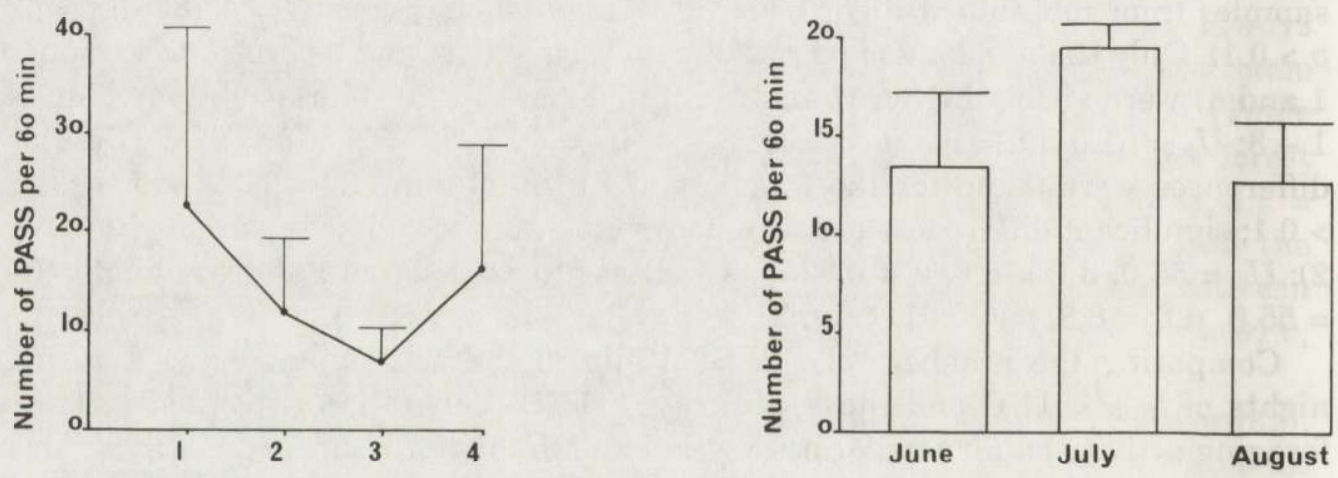

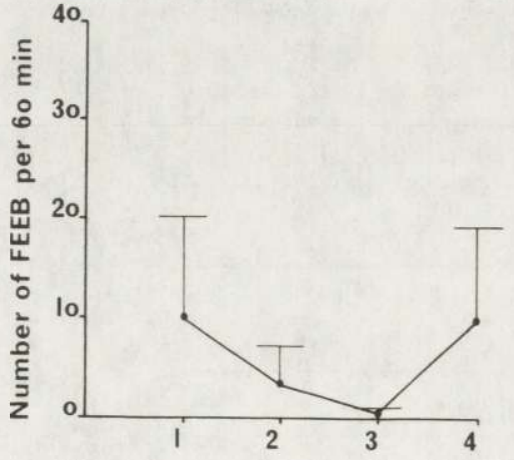

Fig. 2. The mean numbers $(+\mathrm{SE})$ of passes $/ 60$ min and $\mathrm{FEEB} / 60 \mathrm{~min}$ in the subsequent four hours of observation.

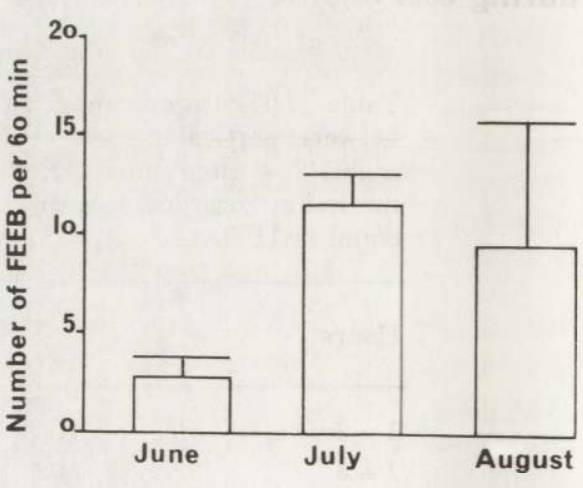

Fig. 3. The mean numbers $(+\mathrm{SE})$ of passes $/ 60$ $\mathrm{min}$ and FEEB/60 min in the three months of the summer season. 
A slight directly proportional dependence of the bats' activity on night temperature was found during the whole period of study for data pooled for three habitats (rivers, forest edge, villages), yet with no statistical significance ( $Y=43.9$ $+1.08 x ; R^{2}=0.0169$, d.f. $=13$, ns). Regression analysis for each habitat separately was impossible due to insufficient sample sizes.

\section{Discussion}

The differences in the activity of noctule bats in the Białowieża Primeval Forest turned out to be very significant. The discovered hierarchy in habitat preferences (riverside, forest-meadow ecotone, village and finally, dense forest; Fig. 1) did not change throughout the 3-month period of observation. In numerous works (Racey and Swift 1985, McAney and Fairley 1988, Walsh and Mayle 1991), the highest activity of bats (e.g. from the genera Nyctalus, Pipistrellus, Rhinolophus and Myotis) was noted near waters. The territory of this research did not include standing waters; however, it turned out that forest rivers are also a very convenient habitat for the species' activity.

The long-range hunting strategy of noctule bats consists in catching insects in fast flights over open areas. Wings of this species are comparatively long and narrow; adapted to high speed but providing less manoeuvrability. The echolocational pulses (types FM and CF, long ( 6 to $25 \mathrm{~ms}$ ) signals of a slow rhythm, emitted at the frequency of about 18 to $25 \mathrm{kHz}$ ) are also an adaptation to hunting from a long distance over an open area (Ahlén 1981, Barclay 1986, Baagøe 1987, Neuweiler 1990). Due to these adaptations, the main feeding grounds of the bats are open territories (riverside and forest edge). The above habitats are ecotones, therefore, they are characterized by the variety and abundance of the potential food. The villages are regions of a higher night temperature than the surrounding forest, and they are places, where swarming insects occur plentifully. The occurrence of the insects is facilitated also by the presence of domestic animals. The villages, as an anthropogenic element of the primeval forest landscape, may constitute an optional feeding ground for the studied species. Nevertheless, the villages do not offer hiding-places. The noctule bat, unlike other species of bats living on this territory, rarely uses buildings as summer shelters (e.g. Kowalski and Ruprecht 1983).

The activity of noctule bats in the examined forests was found to be low, but this does not mean that the species avoids woods. According to my earlier observations, thinner parts of forests and clearings caused by windstorms (frequent in natural forests) are enclaves in which noctule bats feed at times. Moreover, in dense woods, other bat species of a different hunting strategy were found (Myotis nattereri and Pipistrellus spp.).

In the studied habitats, the bimodal overnight activity of the noctule bats was noted throughout the whole season. The two-peak rhythm of feeding is connected 
with the varying access to insects, and is characteristic of most of the bats feeding on flying insects (Erkert 1982). Many authors, e.g. Williams (1939) and Barclay (1991) state that the activity of flying night insects (measured by their biomass) reaches maximum after sunset. Morgan and Waddell (1961), and Lewis and Taylor (1965) found that in the European climactic conditions, the activity rhythm of insects is two-peak with a visible decrease in the middle of the night. Kronwitter (1988), carrying on observations on, among other animals, a colony of noctule bats, noted that the bats make 2 to 3 flights per night, and that the number of flights depends on the weather conditions (at lower temperatures, there is no flight in the middle of the night). According to O'Shea and Vaughan (1977), who discovered the two-peak rhythm of activity in the American Antrozous pallidus, after the first peak the bats were no longer hungry, and the middle-night pause allowed them to save energy during the time of the lowest hunting efficiency.

Big differences in the activity rhythm of noctule bats were recorded between particular nights. One may assume that to a high degree these differences were influenced by weather conditions. The differences between nights of minimum temperature lower and higher than $11^{\circ} \mathrm{C}$ prove that air temperature determines the hunting strategy. During warm nights, the morning activity was considerable, and distinct peaks of activity disappeared. Certain activity in the middle of the night was also noted then. In turn, because low temperatures limited the abundance of prey during cool nights, the bats intensifies their foraging shortly after sunset. Practically, they relinquished the morning activity since its time was between 3 and 5 a.m., i.e. the coolest period of the day.

The discovered intraseasonal differences of activity may be caused by weather conditions and by the species' biology. In July, young bats were observed on the study area. Their presence certainly increased the number of the recorded individuals. The relatively high and steady temperature at that time must have influenced positively the food supply. In southern Sweden, like in the Białowieża Primeval Forest where summer ends early, the highest density of flying night insects was noted in July (de Jong and Ahlén 1991). In August, with the average temperatures being higher, the variations in air temperature in Białowieża were bigger, and the month's end was cold (the minimum night temperatures were below $10^{\circ} \mathrm{C}$ ). The lower activity of noctule bats at that time can also be connected with the dispersion of the young animals, and an early beginning of the seasonal migrations. Taking into account the above factors enables to explain why no significant dependence of the bats' activity on air temperature was found throughout the whole season. Despite higher temperatures in August, the bats' activity was influenced primarily by behavioral factors.

No increase in the feeding activity aimed at improving the individuals' condition before hibernation was noted towards the end of the season, although such an increase was observed in other research works (McAney and Fairley 1988). This situation may have been caused by a temperature drop at the end of August. Low temperatures $\left(t_{\min }<10^{\circ} \mathrm{C}\right)$ maintained then for the greater part of September. At 
that time, the population of noctule bats visually observed on the feeding grounds was small. Due to lack of data from previous years, it is not possible to state whether such an early an end to summer activity is typical for these regions, where the climate is quite severe; or whether it resulted from a coincidence of unfavorable thermal conditions during 1991.

Acknowledgements: I am cordially thankful to all who have contributed to the creation of this work. I owe acknowledgements especially to M. Bebłowska, I. Hajdamowicz and H. Zalewska for invaluable help in the field work, as well as to Dr B. Jędrzejewska, Dr W. Bogdanowicz and Prof. Z. Pucek for helpful comments during the elaboration of the results, and the drafting of the text. I thank the Bat Research Fund for Eastern Europe (c/o P. Lina, Leiden, Holland) which kindly granted the equipment used in this study.

\section{References}

Ahlén I. 1981. Identification of Scandinavian bats by their sounds. Swedish Univ. Agric. Sci., Dept. Wildl. Ecol., Uppsala, Report 6: $1-56$.

Ahlén I. 1989. European Bat Sounds, 29 species Recorded in the Field. Swedish Univ. Agric. Sci., Uppsala. Audio cassette.

Baagøe H. 1987. The Scandinavian bat fauna: adaptative wing morphology and free flight in the field. [In: Recent advances in the study of bats. M. B. Fenton, P. Racey and J. M. V. Rayner, eds]. Cambridge Univ. Press, Cambridge: $57-74$.

Barclay R. M. R. 1986. The echolocation calls of hoary (Lasiurus cinereus) and silver-haired (Lasionycteris noctivagans) bats as adaptations for long-versus short-range strategies and the consequences for prey selection. Can. J. Zool. 64: $2700-2705$.

Barclay R. M. R. 1991. Population structure of temperate zone insectivorous bats in relation to foraging behaviour and energy demand. J. Anim. Ecol. 60: 165 - 178.

Erkert H. G. 1982. Ecological aspects of bat activity rhythms. [In: Ecology of bats. T. H. Kunz, ed.] Plenum Press, New York - London: 201 - 242.

Faliński J. B. 1986. Vegetation dynamics in temperate lowland primeval forests. Dr W. Junk Publishers, Dordrecht - Boston Lancaster: 74 - 111.

Furlonger C. L., Dewar H. J. and Fenton M. B. 1987. Habitat use by foraging insectivirous bats. Can. J. Zool. 65: $284-288$.

Gaisler J., Hanák V. and Dungel J. 1979. A contribution to the population ecology of Nyctalus noctula (Mammalia: Chiroptera). Acta Sc. Nat. Brno 13 (1): 1 - 38.

Griffin D. R., Webster F. A. and Michael C. R. 1960. The echolocation of flying insects by bats. Anim. Behav. 8: $141-154$.

Jong J. de and Ahlén I. 1991. Factors affecting the distribution pattern of bats in Uppland, central Sweden. Hol. Ecol. 14: 92 - 96.

Kowalski K. and Ruprecht A. L. 1983. Bats (Chiroptera). [In: Keys to vertebrates of Poland. Mammals. Z. Pucek, ed.]. Polish Scientific Publishers, Warsaw: $101-154$.

Kronwitter F. 1988. Population structure, habitat use and activity patterns of the Noctule bat, Nyctalus noctula Schreb., 1774 (Chiroptera: Vespertilionidae) revealed by radio-tracking. Myotis, 26: $23-85$.

Lewis T. and Taylor L. R. 1965. Diurnal periodicity of flight by insects. Trans. Royal Ent. Soc. Lond. 116: $393-479$

McAney C. M. and Fairley J. S. 1988. Habitat preference and overnight and seasonal variation in the foraging activity of Lesser Horseshoe Bats. Acta theriol. 33: $393-402$.

Miller L. A. and Degn H. J. 1981. The acoustic behaviour of four vespertilionid bats studied in the field. J. Comp. Physiol. 142: $67-74$. 
Morgan N. C. and Waddell A. B. 1961. Diurnal variation in the emergence of some aquatic insects. Trans. Royal Ent. Soc. Lond. 113: 123 - 134.

Neuweiler G. 1990. Auditory adaptations for prey capture in echolocating bats. Physiol. Rev. 70: $615-641$.

O'Shea T. J. and Vaughan T. A. 1977. Nocturnal and seasonal activities of the pallid bat, Antrozous pallidus. J. Mammal. 58: 269 - 283.

Racey P. A. and Swift S. M. 1985. Feeding ecology of Pipistrellus pipistrellus (Chiroptera: Vespertilionidae) during pregnancy and lactation. I. Foraging behaviour. J. Anim. Ecol. 54: $205-215$.

Ruprecht A. L. 1976. Nowe obserwacje nad nietoperzami (Chiroptera) Białowieży. Prz. zool. 20: $115-123$.

Sokal R. R. and Rohlf F. J. 1981. Biometry. 2nd ed. W. H. Freeman \& Co., New York: $417-453$.

Thomas D. W. 1988. The distribution of bats in different ages of Douglas-fir forest. J. Wildl. Manage. 52: $619-626$.

Walsh A. L. and Mayle B. A. 1991. Bat activity in different habitats in a mixed lowland woodland. Myotis 29: 97 - 104.

Williams C. B. 1939. An analysis of four years' captures of insects in a light-trap. I. General survey; sex proportion; phenology; and time of flight. Trans. Royal Ent. Soc. Lond. 89: 79 - 132.

Received 16 November 1992, accepted 15 December 1992. 